\title{
Education is Positively Associated with Macular Pigment: the Irish Longitudinal Study on Ageing (TILDA)
}

\author{
John Nolan \\ Waterford Institute of Technology \\ Joanne Feeney \\ Trinity College Dublin \\ Rose Anne Kenny \\ Trinity College Dublin
}

See next page for additional authors

Follow this and additional works at: https://arrow.tudublin.ie/otpomart

\section{Recommended Citation}

Nolan, J.M., Feeney, J. \& Kenny, R.A. (2012). Education is Positively Associated with Macular Pigment: the Irish Longitudinal Study on Ageing (TILDA). Investigative Ophthalmology and Visual Sciences, vol. 53, no. 12, pg. 7855-61. doi:10.1167/iovs.11-9367

This Article is brought to you for free and open access by ARROW@TU Dublin. It has been accepted for inclusion in Articles by an authorized administrator of ARROW@TU Dublin. For more information, please contact arrow.admin@tudublin.ie, aisling.coyne@tudublin.ie, gerard.connolly@tudublin.ie. Funder: European Research Council, Irish Department of Health, Atlantic Philanthropies, Irish Life Insurance Co.

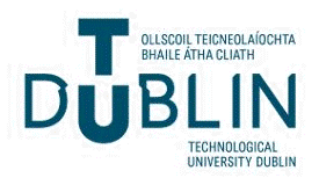




\section{Authors}

John Nolan, Joanne Feeney, Rose Anne Kenny, Hilary Cronin, Claire O'Regan, George Savva, James

Loughman, Ciaran Finucane, Eithne Connolly, Katie Meagher, and Stephen Beatty

This article is available at ARROW@TU Dublin: https://arrow.tudublin.ie/otpomart/30 


\title{
Education Is Positively Associated with Macular Pigment: The Irish Longitudinal Study on Ageing (TILDA)
}

\author{
John M. Nolan, ${ }^{1,2}$ Joanne Feeney, ${ }^{3}$ Rose Anne Kenny, ${ }^{3}$ Hilary Cronin, ${ }^{3}$ Claire O'Regan, ${ }^{3}$ \\ George M. Savva, ${ }^{3}$ James Loughman, ${ }^{4}$ Ciaran Finucane, ${ }^{3}$ Eithne Connolly, ${ }^{1,2}$ Katie Meagher, ${ }^{1}$ \\ and Stephen Beatty ${ }^{1,2}$
}

Purpose. The three carotenoids lutein, zeaxanthin, and mesozeaxanthin, are found at the macula and referred to as macular pigment (MP). This study was undertaken to investigate determinants of MP in a large randomly selected sample from the Republic of Ireland (as part of The Irish Longitudinal Study on Ageing [TILDA]).

MethoDs. MP optical density (MPOD) was measured using customized heterochromatic flicker photometry in 4373 participants. Sociodemographic and self reported health data was obtained using computer assisted personal interview (CAPI).

Results. Mean (SD) MPOD for the study group was 0.203 (0.156) with a range of 0 to 1.01. MPOD was higher for participants with secondary education (mean $[\mathrm{SD}]=0.205$ [0.148]) than for those with only primary education or no education (mean $[\mathrm{SD}]=0.183[0.113] ; P<0.001$ ). MPOD was also higher for those with tertiary education (mean $[\mathrm{SD}]=$ $0.232[0.231])$ compared with primary/no education or secondary education $(P<0.001$ for both comparisons).

Conclusions. We report that MP is lower amongst those participants of a population-representative study who did not have secondary or third level education when compared with participants who had such education. Given the emerging evidence that MP is important for visual performance and comfort, and given the putative protection that this pigment confers against AMD (especially important in the context of increased risk of AMD in this social group), public health

From the 1 Department of Chemical and Life Sciences, Waterford Institute of Technology, Waterford, Ireland; Macular Pigment Research Group; the 2Institute of Vision Research, Whitfield Clinic, Butlerstown North, Cork Road, Waterford, Ireland; ${ }^{3}$ The Irish Longitudinal Study on Ageing, University of Dublin, Trinity College, Dublin, Ireland; the Irish Longitudinal Study on Ageing research group; and the toptometry Department, Dublin Institute of Technology, Dublin, Ireland; Macular Pigment Research Group.

Supported by European Research Council (ERC) (JMN). TILDA is funded by An Roinn Sláinte (Irish Department of Health), The Atlantic Philanthropies, and Irish Life.

Submitted for publication December 21, 2011; revised April 10, June 29, August 20, and September 26, 2012; accepted October 17, 2012.

Disclosure: J.M. Nolan, None; J. Feeney, None; R.A. Kenny, None; H. Cronin, None; C. O'Regan, None; G.M. Savva, None; J. Loughman, None; C. Finucane, None; E. Connolly, None; K. Meagher, None; S. Beatty, None

Corresponding author: John M. Nolan, Macular Pigment Research Group, Vision Research Centre, Carriganore House, Waterford Institute of Technology, West Campus, Carriganore, Waterford, Ireland;jmnolan@wit.ie.

Investigative Ophthalmology \& Visual Science, Month 2012, Vol. 53, No. 0 Copyright 2012 The Association for Research in Vision and Ophthalmology, Inc. measures aimed at improving diet for this at-risk population need to be considered. (Invest Ophthalmol Vis Sci. 2012; 53:000-000) DOI:10.1167/iovs.11-9367

M acular pigment (MP) accounts for the yellow coloration of the central retina and is composed of three carotenoids: lutein $(\mathrm{L})$, zeaxanthin $(\mathrm{Z})$, and meso-zeaxanthin (meso-Z). ${ }^{1,2}$ MP is entirely of dietary origin as carotenoids cannot be synthesized de novo in mammals. ${ }^{3}$ The role of MP relates to its blue light filtering properties and its antioxidant potential. ${ }^{4,5}$ There is a growing consensus that MP is important for optimal visual performance, $, 6,7$ and it is biologically plausible that this pigment protects against AMD, the leading cause of blind registration in the developed world. ${ }^{4,5}$

Beyond diet, the determinants of MP may include genetic background $^{8}$ and known and putative risk factors for AMD (e.g., age, tobacco use, obesity, cumulative exposure to light, ethnicity). ${ }^{9}$ However, studies conducted to date have been based on convenience or volunteer samples recruited from local populations, which are often limited by small sample size and selection bias.

The Irish Longitudinal Study on Ageing (TILDA) is a prospective cohort study aimed at providing valid and reliable data relating to older people and the ageing population in Ireland. ${ }^{10}$ TILDA describes the social, economic, and health status of older Irish adults and aims to identify the factors that influence healthy ageing. At baseline, TILDA has recruited a nationally representative sample of 8175 participants aged 50 years and older. MP optical density (MPOD) was measured in 4373 of these TILDA participants.

In this manuscript, we report the first population-based study, and the largest of its kind, designed to investigate determinants of MP in a large randomly selected sample from the Republic of Ireland.

\section{Methods \\ Sampling}

The study design of TILDA has been described in detail previously. ${ }^{10}$ In brief, a sample of 8175 older adults representative of the population of Ireland aged 50 and over participated in the study. The sampling frame used was the Irish GeoDirectory, a comprehensive and up-to-date listing and mapping of all residential addresses in the Republic of Ireland compiled by 'an Post' (the Irish Postal Service) and Ordnance Survey Ireland. An initial multi-stage probability sample of addresses was chosen by means of the RANSAM sampling procedure, ${ }^{11}$ developed by the Economic and Social Research Institute. All household residents aged greater than or equal to 50 years were eligible to participate in the study. The spouses/partners (of any age) of participants were also invited to participate. However, only respon- 
dents' aged greater than or equal to 50 years were included in the current analyses. The overall response rate in TILDA was 62\% ( $n=$ 8175). Comparison of the TILDA sample with the Irish population using data from the Quarterly National Household Survey (QNHS, 2010; provided in the public domain by Central Statistics Office, Cork, Ireland, http://www.cso.ie) revealed that individuals with lower levels of educational attainment were under represented in TILDA. Also, there were small differences in the response rate by age and sex groupings. To control for this differential nonresponse by age, sex, and level of education, and eliminate it as a source of potential bias, weights were generated and applied in all analyses (see statistical analysis below)

\section{Participants and Data Collection}

Wave 1 of TILDA comprised three separate components: a face-to-face interview, a self completion questionnaire, and a health assessment. For the face-to-face interview, participants were visited in their own homes by trained professional social interviewers. Information on health, social, and economic domains were captured using computer assisted personal interviewing (CAPI). ${ }^{12}$ For details of the CAPI questionnaire used in TILDA, please see http://www.ucd.ie/issda/ data/tilda (provided in the public domain by Irish Social Science Data Archive, University College Dublin, Dublin, Ireland). Of relevance to the current analysis, participants were asked whether they had ever been told by a doctor that they had any of the following conditions: high cholesterol, high blood pressure, AMD, cataracts, or glaucoma. The self report data obtained here must, therefore, be interpreted with appreciation of its limited nature. Participants were also asked whether they currently smoked or had ever smoked cigarettes, cigarillos, or a pipe regularly (daily for at least a year). Participants were then classified as never having smoked, past smokers, or current smokers. The number of cigarettes smoked daily was also recorded. Physical activity was assessed using The International Physical Activity Questionnaire (IPAQ). ${ }^{13}$ The short form (8 items) of this questionnaire was administered to assess the amount of time per week spent performing physical activities from walking to vigorous exercise, and the amount of time spent sitting (inactivity). From this, participants were classified as undertaking a low, moderate, or high level of physical activity according to the IPAQ scoring protocol (provided in the public domain by Karolinska Institutet, Stockholm, Sweden, at http://www.ipaq.ki.se/ scoring.pdf).

Following completion of the interview, participants were asked to complete a self administered questionnaire and were invited to participate in the health assessment component of the study. In order to minimize participant bias, participants had the option of attending either one of two dedicated health centers or having a modified assessment carried out in their own home if travel to a health center was not practical. A total of 5036 participants opted for a health center assessment and 861 underwent a home assessment. Health assessments were carried out by trained research nurses who followed standard operating procedures and were subject to regular quality control. Assessments of vision and MP were only conducted on those participants who attended a health assessment center. Corrected visual acuity (VA) was measured in both eyes using an Early Treatment Diabetic Retinopathy Study (ETDRS) LogMAR chart at a test distance of four meters using the subjects existing refractive correction where relevant. ${ }^{6}$ The eye with the best VA was chosen for the MP assessment.

\section{Assessment of Macular Pigment Optical Density}

MPOD was measured using the Macular Metrics Densitometer (Macular Metrics, Rehoboth, MA) by heterochromatic flicker photometry (HFP). The device was modified specifically for the TILDA study from the device originally described by Wooten et al. ${ }^{14}$ In order to measure MPOD, the participant viewed a stimulus that alternated between a wavelength band absorbed by MP and one that was not. MPOD was measured at the foveal center at the commonly reported eccentricity of $0.5^{\circ}$ (achieved using a $1^{\circ}$ stimulus). The reference point was at circa $7^{\circ}$ of eccentricity (achieved using a $2^{\circ}$ diameter disc). The radiance of the wavelength band absorbed by MP was adjusted in order to minimize the participants' percept of flicker. The range of alternation rates where flicker is not perceived is called the null zone. Primarily because of interindividual differences in temporal (e.g., flicker) sensitivity, it is optimal to customize the HFP task for each participant by selecting the alternation rate to achieve a null zone and a precise setting. This has been termed customized HFP (cHFP), $, 9,15$ and a full description of this method used to measure MP in the TILDA study has already been published by our group. ${ }^{16}$ Of the 5036 participants who attended a health assessment center, 4373 participants successfully completed the MPOD assessment. Reasons for participants' inability to undergo full MPOD measurement included: poor fixation, not being able to follow instructions, or retinal pathology. A further 93 participants were excluded from analysis due to poor visual acuity (VA worse than or equal to 0.5 on the LogMAR scale). This left 4280 participants suitable for this analysis.

Recruitment for the first wave of TILDA began in October 2009 and fieldwork was completed in February 2011. Health assessments were completed in July 2011.

This study was approved by the Faculty of Health Sciences Research Ethics Committee of Trinity College Dublin, and participants provided written informed consent prior to participation in the study. All experimental procedures adhered to the tenets of the Declaration of Helsinki.

\section{Statistical Analysis}

The statistical package for the social sciences (Version 12; StataCorp LP, College Station, TX) was used for all analyses. To account for the fact that the study response rate varied between different subgroups of the population, inverse probability weights were calculated for the main sample (CAPI participants) using the Quarterly National Household Survey (QNHS 2010). As the probability of participation in the further health center assessment (and, thus, assessment of MPOD) also varied according to geographic location, health, education, age, smoking, and marital status, a specific 'health center weight' was created incorporating the CAPI weight. For a more detailed description of the weighting procedure used in TILDA, please see recent report from the TILDA group. ${ }^{17}$

Bivariate relationships between MPOD and demographic, health, and lifestyle factors were explored using linear regression with Wald tests for between-group differences, as well as graphically using box plots. To estimate the independent effect of each explanatory variable on MPOD, a multiple linear regression analysis was conducted.

The distribution of MPOD appears slightly skewed, and so as a sensitivity analysis the regression was repeated using a square root transformation of the MPOD as the dependent variable.

\section{Results}

\section{Demographic, Health, and Lifestyle Factors: Associations with MPOD}

MPOD by demographic, self reported health and lifestyle variables for participants who met the inclusion criteria are summarized in Table 1. Mean (SD) MPOD for the study group was $0.203(0.156)$ with a range of 0 to 1.01 . Visual acuity ranged from -0.3 to 0.48 (Mean $[S D]=0.049[0.153]$ ) on the LogMAR scale and was not significantly correlated with MPOD (Pearson's correlation $r=-0.020, P>0.10$ ).

Age. The participants ranged in age from 50 to 93 years (mean $[\mathrm{SD}]=62.49[8.89]$ ). Participants were divided into three age groups: 50 to 64 years (mean MPOD $=0.200$ ), 65 to 74 years $($ mean $M P O D=0.204)$, and 75 years and over $($ mean MPOD $=0.215$; Table 1$)$. Age group was not significantly 
TABLE 1. MPOD by Demographic, Health, and Lifestyle Variables

\begin{tabular}{|c|c|c|c|c|c|c|c|}
\hline \multirow[b]{2}{*}{ Variable } & \multirow[b]{2}{*}{$n$} & \multicolumn{5}{|c|}{ MPOD } & \multirow[b]{2}{*}{ Sig. } \\
\hline & & Mean Percentile & SD & $25^{\text {th }}$ & $50^{\text {th }}$ & $75^{\text {th }}$ & \\
\hline \multicolumn{8}{|l|}{ Age* $^{*}$} \\
\hline 50 to 64 & 2835 & 0.200 & 0.157 & 0.075 & 0.183 & 0.296 & \multirow[t]{3}{*}{0.339} \\
\hline 65 to 74 & 1119 & 0.204 & 0.175 & 0.075 & 0.183 & 0.298 & \\
\hline 75 to 93 & 327 & 0.215 & 0.114 & 0.090 & 0.212 & 0.310 & \\
\hline \multicolumn{8}{|l|}{ Sex } \\
\hline Male & 2005 & 0.187 & 0.146 & 0.064 & 0.164 & 0.281 & \multirow[t]{2}{*}{0.000} \\
\hline Female & 2276 & 0.217 & 0.165 & 0.089 & 0.208 & 0.315 & \\
\hline \multicolumn{8}{|l|}{ Education } \\
\hline Primary/none & 866 & 0.183 & 0.113 & 0.060 & 0.166 & 0.271 & \multirow[t]{3}{*}{0.000} \\
\hline Secondary & 1794 & 0.205 & 0.148 & 0.082 & 0.193 & 0.304 & \\
\hline Tertiary/higher & 1621 & 0.232 & 0.231 & 0.099 & 0.213 & 0.336 & \\
\hline \multicolumn{8}{|l|}{ Smoker } \\
\hline Smoked & 1957 & 0.209 & 0.166 & 0.080 & 0.196 & 0.307 & \multirow[t]{3}{*}{0.001} \\
\hline Past smokers & 1710 & 0.207 & 0.161 & 0.083 & 0.187 & 0.307 & \\
\hline Current smokers & 614 & 0.181 & 0.123 & 0.060 & 0.167 & 0.271 & \\
\hline \multicolumn{8}{|l|}{ Blood pressure } \\
\hline Normal & 2870 & 0.208 & 0.160 & 0.082 & 0.191 & 0.303 & \multirow[t]{2}{*}{0.011} \\
\hline High & 1411 & 0.193 & 0.148 & 0.065 & 0.180 & 0.292 & \\
\hline \multicolumn{8}{|l|}{ Cholesterol levels } \\
\hline Normal & 2492 & 0.199 & 0.152 & 0.075 & 0.184 & 0.295 & \multirow[t]{2}{*}{0.141} \\
\hline High & 1789 & 0.207 & 0.161 & 0.080 & 0.190 & 0.305 & \\
\hline \multicolumn{8}{|l|}{ BMI, $\mathrm{kg} / \mathrm{m}^{2} \dagger$} \\
\hline Normal $(<25)$ & 663 & 0.213 & 0.164 & 0.077 & 0.212 & 0.314 & \multirow[t]{3}{*}{0.001} \\
\hline Overweight (25-29.9) & 2207 & 0.208 & 0.156 & 0.087 & 0.190 & 0.308 & \\
\hline Obese $(\geq 30)$ & 1411 & 0.190 & 0.152 & 0.062 & 0.172 & 0.285 & \\
\hline \multicolumn{8}{|l|}{$\mathrm{AMD} \neq$} \\
\hline No & 4214 & 0.202 & 0.156 & 0.076 & 0.186 & 0.298 & \multirow[t]{2}{*}{0.010} \\
\hline Yes & 60 & 0.258 & 0.157 & 0.170 & 0.250 & 0.346 & \\
\hline \multicolumn{8}{|l|}{ Family history AMD } \\
\hline No/don't know & 4059 & 0.201 & 0.154 & 0.076 & 0.185 & 0.297 & \multirow[t]{2}{*}{0.001} \\
\hline Yes & 222 & 0.245 & 0.194 & 0.109 & 0.231 & 0.361 & \\
\hline \multicolumn{8}{|l|}{ Exercise } \\
\hline Low & 1145 & 0.207 & 0.155 & 0.078 & 0.191 & 0.306 & \multirow[t]{3}{*}{0.673} \\
\hline Moderate & 1555 & 0.204 & 0.158 & 0.084 & 0.187 & 0.297 & \\
\hline High & 1546 & 0.198 & 0.155 & 0.075 & 0.184 & 0.296 & \\
\hline Glaucoma & & & & & & & \\
\hline No & 4191 & 0.203 & 0.157 & 0.077 & 0.185 & 0.299 & \\
\hline Yes & 83 & 0.196 & 0.140 & 0.080 & 0.171 & 0.266 & 0.933 \\
\hline Cataracts & & & & & & & \\
\hline No & 3950 & 0.203 & 0.158 & 0.077 & 0.187 & 0.299 & 0.665 \\
\hline Yes & 324 & 0.202 & 0.143 & 0.078 & 0.190 & 0.307 & \\
\hline
\end{tabular}

$P$ values reflect the probability asseciated with the given $F$ statistic. Data is weighted. Sig., significance.

* Age: the rationale for our age divisjon is as follows: (i) this division gives a reasonable number of groups and a reasonable number in each group, (ii) they represent the cut=off where a change in life circumstances is likely to occur (at least around age 65), and (iii) they correspond to groupings used in previously published cohort studies.

† 18 individuals had a BMI of less than 18.5 (minimum of 16.85)

₹ We did not ask the subjects to distinguish between early and late stage AMD.

associated with MPOD in the bivariate model $(P=0.33$; Table 1).

Sex. Females were found to have higher MPOD (mean $=$ 0.217 ) than males (mean $=0.187$ ), and this difference was statistically significant, $(P<0.001$; Table 1 , Figure $)$.

Education. Education was found to be significantly associated with MPOD $(P<0.001$; Table 1 , Figure $)$ MPOD was higher for participants with secondary education (mean $=$ 0.205) than for those with only primary education or no education (mean $=0.183 ; P<0.001$ ). MPOD was also higher for those with tertiary education (mean $=0.232$ ) compared with primary/no education or secondary education $(P<0.001$ for both comparisons). 


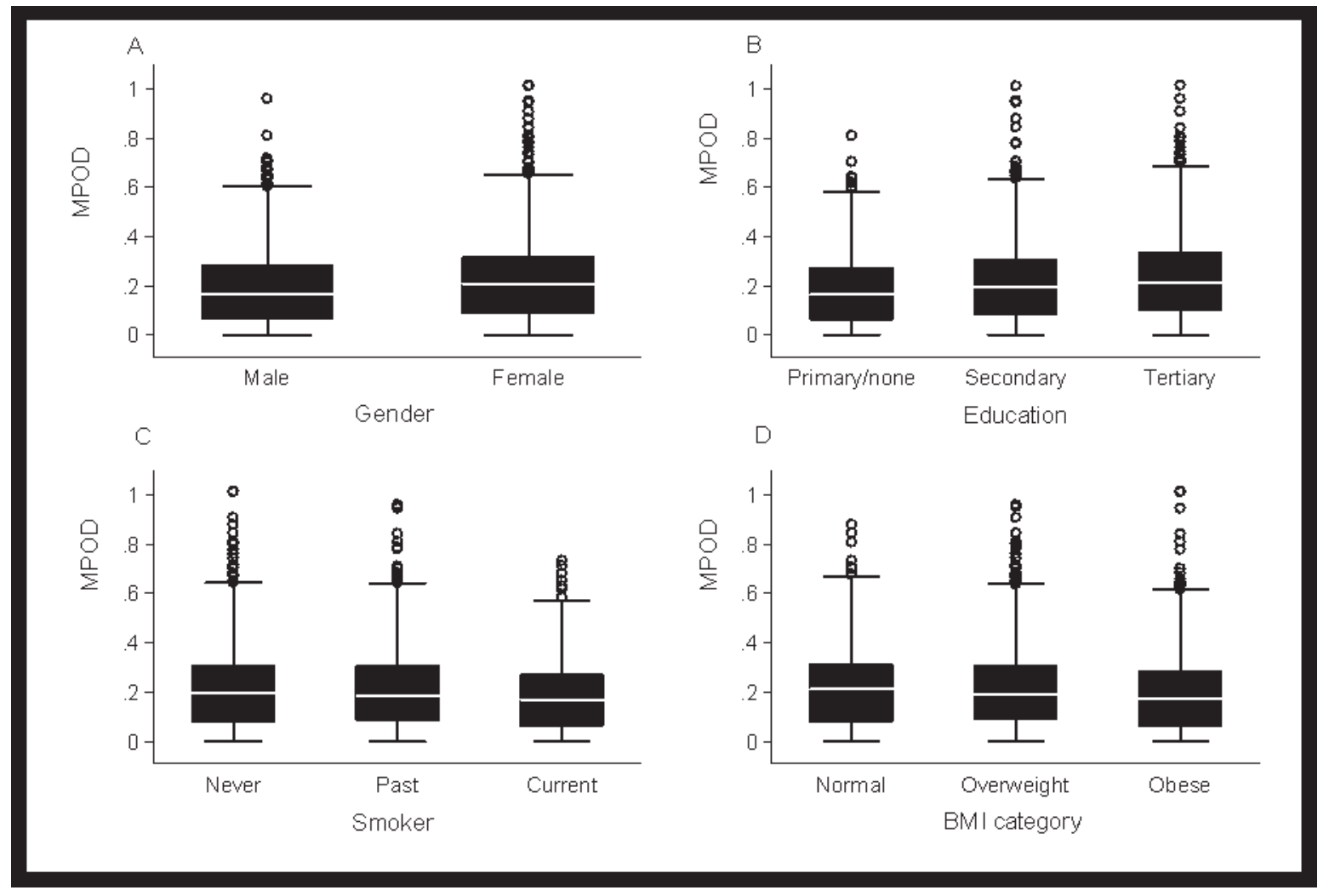

Figure. Box plots of MPOD by (A) sex, (B) education, (C) smoking status, and (D) BMI category.

Smoking. Smoking status was significantly associated with MPOD $(P<0.001$; Table 1). Current smokers had lower MPOD (mean $=0.181)$ than both past smokers $($ mean $=0.209)$ and those who had never smoked (mean $=0.207$ ), and this difference was statistically significant $(P<0.001$ for both comparisons; Figure). There was no significant difference between past smokers and those who had never smoked $(P>$ 0.10). Among cigarette smokers, the number of cigarettes smoked per day was significantly and negatively correlated with MPOD (Pearson's correlation: $r=-0.11, P<0.05$ ).

Body Mass Index (BMI). BMI ranged from 16.85 to 43.88 (Mean $[\mathrm{SD}]=28.66[4.92])$. Participants were categorized into normal, overweight, or obese according to their BMI (Table 1). MPOD differed significantly between the three categories $(P<0.001$; Table 1$)$. Individuals who were classified as obese had significantly lower MPOD (mean $=$ 0.190 ) than either overweight individuals (mean $=0.208 ; P<$ 0.01 ) or those with normal weight (mean $=0.213 ; P<0.01$, Figure). The difference in MPOD between overweight individuals and those with normal weight was not statistically significant $(P>0.10)$

High Blood Pressure and High Cholesterol. High blood pressure was associated with lower MPOD. Participants who reported a doctor's diagnosis of high blood pressure had lower MPOD (mean $=0.193$ ) than those who reported normal blood pressure (mean $=0.208$ ), and this difference was statistically significant $(P<0.05$; Table 1$)$. Self-reported high cholesterol was not associated with MPOD.

Exercise. The level of physical activity undertaken by participants (low, moderate, high) was not associated with MPOD (Table 1).
TABLE 2. Multivariate Relationship between Demographic, Health, and Lifestyle Variables, and MPOD

\begin{tabular}{|c|c|c|c|c|}
\hline $\begin{array}{l}\text { Explanatory } \\
\text { Variable }\end{array}$ & $\begin{array}{c}\text { Unstandardized } \\
\text { Beta } \\
\text { Coefficient }\end{array}$ & $\begin{array}{l}\text { Std. } \\
\text { Error }\end{array}$ & $\boldsymbol{T}$ & $\boldsymbol{P}$ \\
\hline Constant & 0.175 & 0.032 & 5.48 & 0.000 \\
\hline Age & 0.001 & 0.000 & 2.44 & 0.015 \\
\hline Sex (female) & 0.027 & 0.006 & 4.65 & 0.000 \\
\hline \multicolumn{5}{|l|}{ Education* } \\
\hline Secondary & 0.020 & 0.006 & 3.16 & 0.002 \\
\hline Third level/higher & 0.046 & 0.007 & 6.50 & 0.000 \\
\hline \multicolumn{5}{|l|}{ Smoking $\dagger$} \\
\hline Past & 0.003 & 0.006 & 0.50 & 0.620 \\
\hline Current & -0.022 & 0.008 & -2.81 & 0.005 \\
\hline BMI & -0.002 & 0.000 & -3.56 & 0.000 \\
\hline High blood pressure & -0.015 & 0.006 & -2.44 & 0.015 \\
\hline High cholesterol & 0.007 & 0.006 & 1.27 & 0.205 \\
\hline \multicolumn{5}{|l|}{ Exercise $\ddagger$} \\
\hline Moderate & -0.008 & 0.007 & -1.09 & 0.278 \\
\hline High & -0.009 & 0.007 & -1.42 & 0.156 \\
\hline AMD & 0.040 & 0.022 & 1.80 & 0.072 \\
\hline Family history AMD & 0.024 & 0.013 & 1.77 & 0.076 \\
\hline Cataracts & -0.012 & 0.011 & -1.05 & 0.295 \\
\hline Glaucoma & -0.009 & 0.019 & -0.49 & 0.622 \\
\hline Visual acuity & -0.021 & 0.019 & -1.10 & 0.271 \\
\hline
\end{tabular}

$r^{2}=0.037$. Dependent variable $=$ MPOD. Data is weighted. Std. Error, Standard Error

* Primary education $=$ control group.

$\dagger$ Never smoked $=$ control group .

$\neq$ Low exercise $=$ control group 


\section{Multivariate Model}

Education, Age, and Sex. Education remained a strong, positive predictor of MPOD after adjusting for covariates; having achieved a secondary or tertiary education were significantly associated with higher MPOD $(P<0.01$ and $P<$ 0.001 , respectively; Table 2 ). While the three age groups did not differ with respect to MPOD in univariate analysis, age (as a continuous variable) was positively associated with MPOD in the multivariate model $(P<0.05$; Table 2$)$. Female sex remained predictive of higher MPOD in the multivariate model $(P<0.001$; Table 2).

Health and Lifestyle Factors. Both current smoking and BMI were significantly associated with lower MPOD after adjusting for covariates $(P<0.01$ and $P<0.001$, respectively; Table 2). High blood pressure also remained a significant predictor of MPOD $(P<0.05$; Table 2$)$.

None of the other health or lifestyle variables were significantly associated with MPOD in the multivariate model.

A sensitivity analysis conducted by applying a square root transformation to the MPOD variable and using the transformed MPOD as the dependent variable in the regression showed no difference with respect to the variables identified as independently associated with MPOD.

\section{Discussion}

We report the first investigation of MP values, and their associations, in the context of a large population-representative cohort.

This population-based study (TILDA) confirms the findings of previous reports with respect to the relationship between MPOD and cigarette smoking (cigarette smoking is the only established modifiable risk factor for AMD), $, 9,18$ and BMI (BMI is a putative risk factor for AMD). ${ }^{19,20}$ Several previous investigations have reported on the association between cigarette smoking and MP.9,18,21-24 Indeed, our data is consistent with these previous reports, which report not only a significant difference in MP between current and non cigarette smokers, but also an inverse dose-response relationship between MP and the number of cigarettes per day in current cigarette smokers. ${ }^{9,18}$ Possible explanations to account for less MP among cigarette smokers when compared with non cigarette smokers include a poor diet (with consequentially reduced levels of antioxidants) ${ }^{25}$ and/or increased overall oxidant load, which is known to be associated with tobacco use. ${ }^{26}$

Of interest (as noted above), cigarette smoking is established as an important and modifiable risk factor for AMD, with studies consistently demonstrating an increased prevalence of late AMD (i.e., AMD that effects vision) in association with tobacco use. ${ }^{27,28}$

Also, consistent with most previous reports, we found a significant and inverse relationship between BMI and MPOD. ${ }^{9,19,20,29-31}$ Some investigators have suggested that adipose tissue acts as a sink/reservoir for the macular carotenoids. ${ }^{19,20,32}$ Therefore, variation in a person's body fat may influence carotenoid concentrations in serum and host tissues such as the retina. In addition, obesity has been shown to result in an unfavorable high ratio of circulating low density to high density lipoproteins (LDL: HDL) ${ }^{33}$ Given that HDL cholesterol is known to be the most efficient transporter of $\mathrm{L}$ and $\mathrm{Z},{ }^{34}$ reduced HDL in obese individuals may, therefore, impair transport and delivery of the macular carotenoids to the retina (host tissue). It is also possible that the finding of less MPOD seen in obese subjects when compared with nonobese subjects may simply reflect a poor diet among these individuals, as it has been demonstrated that obesity is associated with reduced dietary intake of the macular carotenoids. ${ }^{19,35}$ Also, it is interesting to point out that diabetes (a condition influenced by socioeconomic status and education $)^{36}$ has also been associated with lower levels of MPOD. ${ }^{31,37}$

Of interest, and to our knowledge, a novel finding was that self reported high blood pressure was associated with lower MPOD. Participants who reported a doctor's diagnosis of high blood pressure had lower MPOD (mean OD $=0.193$ ) than those who reported normal blood pressure (mean OD = $0.208)$, and this difference was statistically significant $(P<$ 0.05 ; Table 1). It is difficult to explain the association between blood pressure and MPOD, but it could simply be related to dietary habits, as it is known that a poor diet lacking in fruits and vegetables (the source of MP) is associated with increased risk of high blood pressure. ${ }^{38}$ However, it was not feasible to collect data on dietary intake of the carotenoids in TILDA because of limited time allocated for each participant's visit (this limitation is discussed further below).

Mean MPOD values reported here are somewhat lower than those of previous investigators, although it should be noted that most previous studies have typically been conducted using younger samples and may not have been representative of their populations. In this older age group $(\geq 50)$, we found that age was positively related with MPOD, which is inconsistent with most reports.9,39 However, it is worth noting that the Carotenoids in Age-Related Eye Disease Study (CAREDS), which recruited only female subjects who were of comparable age to TILDA participants, reported no relationship between MP and age. ${ }^{31}$

Of interest, spouses of the primary respondent of any age were also invited to participate in TILDA; however, the numbers enrolled aged less than 50 years were small and not representative of the population, and, therefore, their data was excluded from analysis in this paper. However, analysis of this data shows that this younger age cohort $(<50$ years; data not presented here) had significantly higher MPOD than the older age cohort, which is consistent with the majority of previous reports using HFP (a technique that uniquely remains unaffected by ocular media and therefore unbiased by age) reporting an age-related decline in MP.?

In the current study, we found that education status was a predictor of MPOD, and this is perhaps the most important, and certainly the most novel, finding that we report. Our observation is both unsurprising and intuitive, given that lack of education is a marker for low socio-economic status (SES), which is associated with obesity, tobacco use, and a poor diet, ${ }^{40}$ factors that have been consistently shown to be negative predictors MP. ${ }^{9}$ However the differences in MPOD between educational attainment groups that we discovered were not substantially attenuated in the multivariate model including BMI and smoking, suggesting that these risk factors do not account for the association between MP and low education. Further, it is tempting to hypothesize that the increased risk of AMD associated with lower education status ${ }^{41}$ is attributable, at least in part, to a lack of MP among persons in this group.

Our finding that educational status is a predictor of MPOD is consistent with the findings of CAREDS published in $2006,{ }^{31}$ which found that level of education in similarly aged US women $(n=1698)$ was significantly correlated with MPOD $(P=0.01)$. The slightly higher correlation in TILDA $(r=0.13 ; P<0.01)$ than CAREDS $(r=$ $0.08 ; P=0.081)$ may reflect the greater diversity in educational levels in the population-based sample of TILDA. The association between education and MPOD in the present study is likely to reflect poorer dietary intake in less educated persons in the Irish population. Although 
dietary data are not available in this sample (TILDA), it is worth noting that the association between education and MPOD in CAREDS was greatly attenuated (and no longer statistically significant $[P=0.38]$ ) after adjusting for dietary intake of $\mathrm{L}$ and $\mathrm{Z}$.

Of interest, although CAREDS used the same macular pigment measuring device, and report MPOD at the same retinal eccentricity $\left(0.5^{\circ}\right)$ as that in the current study, and although the age distribution of subjects is comparable between studies, the average MPOD reported in CAREDS is notably higher than that reported here in the TILDA sample. For example, subjects in CAREDS in the high school group (equivalent to the secondary education group in TILDA) had a mean \pm SD MPOD of $0.34 \pm 0.21$, which compares with 0.20 \pm 0.15 in the secondary education group found in TILDA. This difference of 0.14 OD is clinically meaningful, and may be explained by differences in any of the following variables: sample population, sex (CAREDS only recruited female subjects), dietary intake of $\mathrm{L}$ and $\mathrm{Z}$, other dietary factors (e.g., amount of fat in diet), light exposure, among others. We believe, however, given the unique sampling method of TILDA, which includes a very large random sample of the population, male and female subjects, and a broad range of socioeconomic status, that our findings and the conclusions drawn from our findings with respect to the relationship between MPOD and education (and other parameters), are more representative of the general population than those reported in CAREDS.

We acknowledge that the failure not to assess dietary intake of the macular carotenoids is a limitation of the current study, as such information would have enriched the study by informing the interpretation of our findings. Importantly, however, this lack of dietary data does not impact on the validity of our findings, and only adversely affects our report in terms of interpretation of those findings. However, we do believe that the causality of our novel and important findings should now be the subject of further and worthwhile study, specifically designed to address that question (e.g., to elucidate the reason for lower MP amongst subjects in lower socio-economic groups). It is also important to note that our novel findings reported here concern the carotenoid level at the target tissue (i.e., macular pigment). We do understand the importance of controlling for potential confounding variables, including diet, but as mentioned above, it was not feasible to do so in the current study given the very large sample size, duration of study visit (already circa two hours), and resources required to assess (with accuracy) dietary intake of the macular carotenoids. Also, the relationship between dietary intake of the macular carotenoids (assessed by food frequency questionnaires and other methods) and MPOD has been consistently poor. Our group typically reports correlations (Pearson correlations) of only $r=0.2$ between dietary intake of L (or Z) and MPOD, thereby explaining less than $10 \%$ of the variance in MPOD in these subjects $(n=$ 828). ${ }^{42}$ Indeed, this is consistent with other published reports. For example, a study by Mares et al. in $2006(n=$ 1698) reported a relationship between diet and MPOD of only $r=0.16,{ }^{31}$ whereas Burke et al. in $2005(n=98)$ reported a relationship of $r=0.24^{29}$ and Bone et al. in 2000 (with a very small sample, $n=19$ ) reported a relationship of $r=0.42 .^{3}$

However, it is important to emphasize that the MP determinants, reported here, albeit remaining statistically significant following a regression model, contribute to an overall and weak composite explanation of only 3.5\% of MP's variability. Given that MP's constituent carotenoids cannot be synthesized de novo in mammals, and given that measures of this pigment are also influenced by genetic background, ${ }^{8}$ the inability to better explain interindividual variability of MP is consistent with observations for tissue concentrations of other compounds that are also exclusively of dietary origin (e.g., vitamin $\mathrm{C}^{43}$ ).

In conclusion, we report that MP is higher in older people with secondary and tertiary education compared with those with only primary education, and that this difference is not explained by higher rates of smoking or obesity in this group. Given the emerging evidence that MP is important for visual performance and comfort, and given the putative protection that this pigment confers against AMD (especially important in the context of increased risk of AMD in this social group), public health measures aimed at improving diet for this at-risk population need to be considered.

\section{Acknowledgments}

We thank the TILDA study group and the many field researchers and research nurses who conducted the tests in TILDA. We also would like to thank Billy Wooten, PhD, for his support and advice on the measurement of MPOD in the TILDA sample.

\section{References}

1. Bone RA, Landrum JT, Tarsis SL. Preliminary identification of the human macular pigment. Vision Res. 1985;25:1531-1535.

2. Neuringer M, Johnson EJ, Snodderly DM, Sandstrom MM, Schalch W. Supplementation of carotenoid-depleted rhesus monkeys with lutein or zeaxanthin: effects on serum and adipose tissue carotenoids and macular pigment. Invest Ophthalmol Vis Sci. 2001;42:1209.

3. Bone RA, Landrum JT, Dixon Z, Chen Y, Lerena CM. Lutein and zeaxanthin in the eyes, serum and diet of human subjects. Exp Eye Res. 2000;71:239-245.

4. Loane E, Kelliher C, Beatty S, Nolan JM. The rationale and evidence base for a protective role of macular pigment in age-related maculopathy. Br J Ophthalmol. 2008;92:11631168.

5. Sabour-Pickett S, Nolan JM, Loughman J, Beatty S. A review of the evidence germane to the putative protective role of the macular carotenoids for age-related macular degeneration. $\mathrm{Mol}$ Nutr Food Res. 2011;10.

6. Nolan JM, Loughman J, Akkali MC, et al. The impact of macular pigment augmentation on visual performance in normal subjects: COMPASS. Vision Res. 2011;51:459-469.

7. Loughman J, Akkali MC, Beatty S, et al. The relationship between macular pigment and visual performance. Vision Res. 2010;50:1249-1256

8. Loane E, Nolan JM, McKay GJ, Beatty S. The association between macular pigment optical density and CFH, ARMS2, C2/BF, and C3 genotype. Exp Eye Res. 2011;93:592-598.

9. Nolan JM, Stack J, O'Donovan O, Loane E, Beatty S. Risk factors for age-related maculopathy are associated with a relative lack of macular pigment. Exp Eye Res. 2007;84:61-74.

10. Kearney PM, Cronin H, O'Regan C, et al. Cohort profile: The Irish Longitudinal Study on Ageing. Int J Epidemiol. 2011;40: 877-884.

11. Whelan BJ. RANSAM: a random sample design for Ireland. Econ Soc Rev. 1979;10:169-174.

12. Craig CL, Marshall AL, Sjostrom M, et al. International physical activity questionnaire: 12-country reliability and validity. Med Sci Sports Exerc. 2003;35:1381-1395.

13. Sainsbury R, Ditch J, Hutton S. Computer assisted personal interviewing. In: Miller R, Brewer J, eds. The A-Z of Social Research. London, England: Sage; 2003:-18-21. 
14. Wooten BR, Hammond BR, Land RI, Snodderly DM. A practical method for measuring macular pigment optical density. Invest Opbthalmol Vis Sci. 1999;40:2481-2489.

15. Stringham JM, Hammond BR, Nolan JM, et al. The utility of using customized heterochromatic flicker photometry (cHFP) to measure macular pigment in patients with age-related macular degeneration. Exp Eye Res. 2008;87:445-453.

16. Nolan JM, Kenny R, O'Regan C, et al. Macular pigment optical density in an ageing Irish population: The Irish Longitudinal Study on Ageing. Opbthalmic Res. 2010;44:131-139.

17. Savva G. In Fifty Plus in Ireland 2011: First Results from The Irish Longitudinal Study on Ageing. Dublin: Trinity College Dublin; 2011.

18. Hammond BR, Wooten BR, Snodderly DM. Cigarette smoking and retinal carotenoids: Implications for age-related macular degeneration. Vis Res. 1996;36:3003-3009.

19. Nolan J, O'Donovan O, Kavanagh $\mathrm{H}$, et al. Macular pigment and percentage of body fat. Invest Ophthalmol Vis Sci. 2004; 45:3940-3950.

20. Hammond BR, Ciulla TA, Snodderly DM. Macular pigment density is reduced in obese subjects. Invest Ophthalmol Vis Sci. 2002; 43:47-50.

21. Curran-Celentano J, Hammond BR, Ciulla TA, Cooper DA, Pratt LM, Danis RB. Relation between dietary intake, serum concentrations, and retinal concentrations of lutein and zeaxanthin in adults in a Midwest population. Am J Clin Nutr. 2001;74:796-802.

22. Hammond BR, Caruso-Avery M. Macular pigment optical density in a southwestern sample. Invest Ophthalmol Vis Sci. 2000;41:1492-1497.

23. Beatty S, Murray IJ, Henson DB, Carden D, Koh HH, Boulton ME. Macular pigment and risk for age-related macular degeneration in subjects from a Northern European population. Invest Ophthalmol Vis Sci. 2001;42:439-446.

24. Broekmans WMR, Berendschot TTJM, Klopping-Ketelaars IAA, et al. Macular pigment density in relation to serum and adipose tissue concentrations of lutein and serum concentrations of zeaxanthin. Am J Clin Nutr. 2002;76:595-603.

25. Dallongeville J, Marecaux N, Fruchart JC, Amouyel P. Cigarette smoking is associated with unhealthy patterns of nutrient intake: a meta-analysis. $J$ Nutr. 1998;128:1450-1457.

26. Beatty S, Koh HH, Henson D, Boulton M. The role of oxidative stress in the pathogenesis of age-related macular degeneration. Surv Opbthalmol. 2000;45:115-134.

27. George S, Rosner B, Seddon JM. Cigarette smoking and omega3 fatty acid intake are associated with age-related macular degeneration: The US Age-Related Macular Degeneration Twin Study. Invest Ophthalmol Vis Sci. 2005;46:995-1001.

28. Tamakoshi A, Yuzawa M, Matsui M, Uyama M, Fujiwara NK, Ohno Y. Smoking and neovascular form of age related macular degeneration in late middle aged males: findings from a casecontrol study in Japan. Br J Ophthalmol. 1997;81:901-904.

29. Burke JD, Curran-Celentano J, Wenzel AJ. Diet and serum carotenoid concentrations affect macular pigment optical density in adults 45 years and older. $J$ Nutr. 2005;135:12081214.
30. Kirby ML, Beatty S, Stack J, et al. Changes in macular pigment optical density and serum concentrations of lutein and zeaxanthin in response to weight loss. Br J Nutr. 2011;105: 1036-1046.

31. Mares JA, Larowe TL, Snodderly DM, et al. Predictors of optical density of lutein and zeaxanthin in retinas of older women in the Carotenoids in Age-Related Eye Disease Study, an ancillary study of the Women's Health Initiative. Am J Clin Nutr. 2006; 84:1107-1122.

32. Johnson EJ. Obesity, lutein metabolism, and age-related macular degeneration: a web of connections. Nutr Rev. 2005;63:9-15.

33. Viroonudomphol D, Pongpaew P, Tungtrongchitr R, et al. The relationships between anthropometric measurements, serum vitamin $\mathrm{A}$ and $\mathrm{E}$ concentrations and lipid profiles in overweight and obese subjects. Asia Pac J Clin Nutr. 2003; 12:73-79.

34. Connor WE, Duell PB, Kean R, Wang Y. The prime role of HDL to transport lutein into the retina: evidence from HDLdeficient WHAM chicks having a mutant ABCA1 transporter. Invest Ophthalmol Vis Sci. 2007;48:4226-4231.

35. Berg CM, Lappas G, Strandhagen E, et al. Food patterns and cardiovascular disease risk factors: the Swedish INTERGENE research program. Am J Clin Nutr. 2008;88:289-297.

36. Connolly V, Unwin N, Sherriff P, Bilous R, Kelly W. Diabetes prevalence and socioeconomic status: a population based study showing increased prevalence of type 2 diabetes mellitus in deprived areas. J Epidemiol Community Health. 2000;54:173-177.

37. Moeller SM, Voland R, Sarto GE, Gobel VL, Streicher SL, Mares JA. Women's Health Initiative diet intervention did not increase macular pigment optical density in an ancillary study of a subsample of the Women's Health Initiative. J Nutr. 2009; 139:1692-1699.

38. MacGregor GA. Nutrition and blood pressure. Nutr Metab Cardiovasc Dis. 1999;9:6-15.

39. Gellermann W, Ermakov IV, Ermakov MR, McClane RW, Zhao DY, Bernstein PS. In vivo resonant Raman measurment of macular pigments in the young and the aging human retina. $J$ of Opthalmol Soc. 2002;19:1172-1186.

40. Winkleby MA, Jatulis DE, Frank E, Fortmann SP. Socioeconomic status and health: how education, income, and occupation contribute to risk factors for cardiovascular disease. Am J Public Health. 1992;82:816-820.

41. Cackett P, Tay WT, Aung T, et al. Education, socio-economic status and age-related macular degeneration in Asians: the Singapore Malay Eye Study. Br J Ophthalmol. 2008;92:13121315.

42. Nolan JM, Stack J, O'Connell E, Beatty S. The relationships between macular pigment optical density and its constituent carotenoids in diet and serum. Invest Ophthalmol Vis Sci. 2007; 48:571-582.

43. Block G, Shaikh N, Jensen CD, Volberg V, Holland N. Serum vitamin $\mathrm{C}$ and other biomarkers differ by genotype of phase 2 enzyme genes GSTM1 and GSTT1. Am J Clin Nutr. 2011;94: 929-937. 